\title{
Chapter 2 \\ Concepts and Methods of Global Assessment of the Economics of Land Degradation and Improvement
}

\section{Ephraim Nkonya, Joachim von Braun, Alisher Mirzabaev, Quang Bao Le, Ho-Young Kwon and Oliver Kirui}

\begin{abstract}
The Economics of Land Degradation (ELD) initiative seeks to develop a science basis for policy actions to address land degradation. The purpose of this chapter is to provide with a conceptual framework and sound and feasible methodological standards for ELD assessments at global and national levels. Only if some basic standards are identified and adhered to, comparative assessments can be conducted between countries and useful aggregation of findings, based on these case studies, can be achieved. Therefore, using the Total Economic Value (TEV) framework, the chapter identifies minimum core standards that need to be adhered to in all country case studies to generate comparable material for international assessment and ELD policy guidance.
\end{abstract}

Keywords Economics of land degradation - Case studies - Natural capital - Total economic value

\section{Introduction}

Healthy land ecosystems (hereafter referred to simply as "land") that function well and ensure their services - are essential to sustainable development, including food security and improved livelihoods. Yet, key services provided by land have habitually been taken for granted and their true value - beyond the market value - has

E. Nkonya $(\bowtie) \cdot$ H.-Y. Kwon

International Food Policy Research Institute, 2033 K Street NW,

Washington, DC 20006, USA

e-mail: e.nkonya@cgiar.org

J. von Braun · A. Mirzabaev · O. Kirui

Center for Development Research (ZEF), University of Bonn,

Water Flex Street 3, D-53113 Bonn, Germany

Q.B. Le

CGIAR Research Program on Dryland Systems (CRP-DS), International Center for Agricultural Research in the Dry Areas (ICARDA), PO Box 950764, Amman 11195, Jordan e-mail: q.le@cgiar.org; q.le@alumni.ethz.ch 
been underrated (von Braun et al. 2013). This pattern of undervaluation of lands is about to change in view of the rapidly rising land prices, which is the result of increasing shortage of land and high output prices (ibid.). Moreover, the value of land ecosystem services is gradually being better understood. Globally, it is estimated that about a quarter of land area is degraded, affecting more than a billion people all over the world (Lal et al. 2012). Land degradation is defined as the persistent reduction of land's biological and/or economic production capacity, or as the long-term loss of land ecosystem functions and services (Safriel 2007; Vogt et al. 2011). Land degradation wreaks its highest toll on the livelihoods and well-being of the poorest households in the rural areas of developing countries (Nachtergaele et al. 2010). Vicious circles of poverty and land degradation, as well as transmission effects from rural poverty and food insecurity to national economies, critically hamper their development process.

Despite the urgent need for preventing and reversing land degradation, the problem has yet to be appropriately addressed (Lal et al. 2012). Policy actions for sustainable land management (SLM) remain inconsistent and often ineffective (Nkonya et al. 2011). Such policy frameworks to combat land degradation need to be supported by evidence-based and action-oriented research (von Braun et al. 2013). The past studies on land degradation had played a useful role in highlighting land degradation as a globally critical issue. However, most of them tended to focus only on simpler relationships, such as, for example, soil erosion and its impact on crop yield, while ignoring the broader values of land ecosystem services, various off-site and indirect costs in their analytical frameworks. The losses from land degradation include not only environmental degradation cost measured directly on-site (e.g., soil loss and nutrient depletion), but also the cost of indirect and off-site environmental impacts (e.g., siltation of water bodies, water pollution, and biodiversity declines) (Foley et al. 2005).

Yet it is empirically challenging to account for all the costs of land degradation. Among major challenges are measurement and valuation of losses in ecosystem benefits due to land degradation (Barbier 2011a, b). Moreover, the double-counting of these ecosystem benefits needs to be avoided - a complex task by itself (Barbier 2010). Processes (e.g. water purification) and benefits (e.g. purified potable water) could be double counted if each is given a separate value (Balmford et al. 2008). The benefits are the end products of the beneficial processes. One approach to avoid double counting in this regard is to only take the value of potable water with different qualities and skip counting of the water purification process. However, it is equally obvious that the conceptual framework for Economic Assessment of Land Degradation and Improvement should not be limited to only more easily measurable direct on-site and off-site costs of land degradation since taking such an approach ignores the intrinsic relationship of ecosystems and will lead to undervaluing the cost of land degradation and benefits of taking action against land degradation. Hence the conceptual framework should be able to accommodate all losses due to land degradation, thus providing guidance and basis for a comprehensive evaluation, even if it means that empirical gaps will be filled not immediately but through a longer-term research. 
This action-oriented focus and the definitions of land and land degradation determine the methodological approaches applied in this book. United Nations Convention to Combat Desertification (UNCCD) (1996) defines land as a terrestrial ecosystem consisting of flora, fauna, hydrological processes and other ecological services beneficial to human beings. The Millennium Ecosystem Assessment (MEA 2005) defines land degradation as long-term loss of on-site and off-site terrestrial ecosystem goods and services, which humans derive from them. These definitions lead to using a comprehensive approach which takes into account both short- and long-term direct and indirect, on-site and off-site benefits of sustainable land management versus the related costs of land degradation. Thus, to be comprehensive, this economic assessment study uses TEV approach, which assigns value to all use and non-use ecosystem services. This means the TEV approach captures the value of ecosystem goods and services and goes beyond the common monetary values of provisioning services used in many past economic studies. Consequently, this approach strives to capture all changes, both degradation and improvement, in ecosystem functions and services attributed to land ecosystems.

The action against land degradation involves preventing the degradation of currently used or usable lands or rehabilitating degraded lands. Action against land degradation is referred here as sustainable land management, which according to TerrAfrica (2006), is generally understood as the "adoption of land systems that, through appropriate management practices, enables land users to maximize the economic and social benefits from the land, while maintaining or enhancing the ecological support functions of the land resources". However, this definition is too general, lacking measurable criteria to guide policy focuses regarding SLM. In this study, "actions against land degradation" are defined as land management which leads to persistent improvement of biological productivity and biodiversity of the land. However, relevant understanding of these criteria has to be based on the usage people expect from the land (i.e., expected land use) and the baseline for assessment. With land intentionally used for agricultural or forest production, long-term soil-driven net primary productivity (NPP), i.e. the net biomass produced by the soil and other natural resources (water and sunlight) without remarkable external inputs (e.g., improved rainfall, fertilizer use, atmospheric fertilization), can be a proxy for SLM or land degradation assessment. However, the treatment of observed biomass productivity trend has to further depend on the baseline of the assessment. Where the initial productivity was already low (degraded), a long-term improvement of soil-driven productivity can reflect SLM. Where the beginning productivity was already high, at least an absence of decline (a steady state) of soil-driven productivity also may indicate SLM. On land used/planned for nature protection, soil-driven NPP is still important, but biodiversity is an additional criterion for SLM. In many cases soil quality and biodiversity support each other, but in some other cases, they may not necessarily be mutually consistent. For example, an invasion of exotic plant species can lead to high biomass productivity but dramatically reduce biodiversity, which is not desirable. Increasing of soil nutrients can reduce plant diversity in some cases (Chapin et al. 2000; Sala et al. 2000; Wassen et al. 2005). The use of soil-based biomass productivity to indicate land degradation 
in these areas may not be relevant to the land-use goal. To include these areas in the land degradation or SLM assessment, in addition to soil resources, other foundational aspects of forest ecosystems (e.g. flora and fauna structures and composition) have to be considered. Thus, using biomass productivity trend alone to indicate land degradation or SLM on such protected areas can give misleading results. Further, there is still a lack of data to more accurately delineate global forest cover into different use regimes.

Land improvement is generally recognized as being closely determined by the increasing of net primary productivity (NPP) of the land, under certain conditions, and the improvement of soil fertility. The NPP trend, approximated by the trend of inter-annual Normalized Difference Vegetation Index (NDVI), can be an indirect indicator of soil degradation or soil improvement if the nutrient source for vegetation/crop growth is solely, or largely, from the soils (i.e., soil-based biomass productivity). In the agricultural areas with intensive application of mineral fertilizers (i.e. fertilizer-based crop productivity), NPP trend (via NDVI trend) principally cannot be a reliable indicator of soil fertility trend (Le 2012). In this case, alternative indicators of soil fertility should be used. Moreover, the elevated levels of $\mathrm{CO}_{2}$ and NOx in the atmosphere (Reay et al. 2008; WMO 2012) can cause a divergence between NPP trend and soil fertility change as the atmospheric fertilization effect has not been substantially mediated through the soil. The rising level of atmospheric $\mathrm{CO}_{2}$ stimulates photosynthesis in plants' leaves, thus increasing NPP, but the soil fertility may not necessarily be proportional to the above ground biomass improvement. The wet deposition of reactive nitrogen and other nutrients may affect positively plant growths as foliate fertilization without significantly contributing to the soil nutrient pool, or compensating nutrient losses by soil leaching and accelerated erosion. The correction of the masking effect of atmospheric fertilization can be done by considering the quantum of biomass improvement in intact vegetation area, using the method proposed in Vlek et al. (2010) and Le et al. (2012). However the result must be evaluated by comparing the spatial corrected NDVI trend pattern with independent indicators, such as ground-measured NPP or soil erosion (e.g. Le et al. 2012).

\section{The Conceptual Framework}

The conceptual framework (Fig. 2.1) categorizes the causes of land degradation into proximate and underlying, which interact with each other to result in different levels of land degradation. Proximate causes of land degradation are those that have a direct effect on the terrestrial ecosystem. The proximate causes are further divided into biophysical proximate causes (natural) and unsustainable land management practices (anthropogenic). The underlying causes of land degradation are those that indirectly affect the proximate causes of land degradation, such as institutional, socio-economic and policy factors. For example, poverty could lead to the failure of land users to invest in sustainable land management practices leading to land 


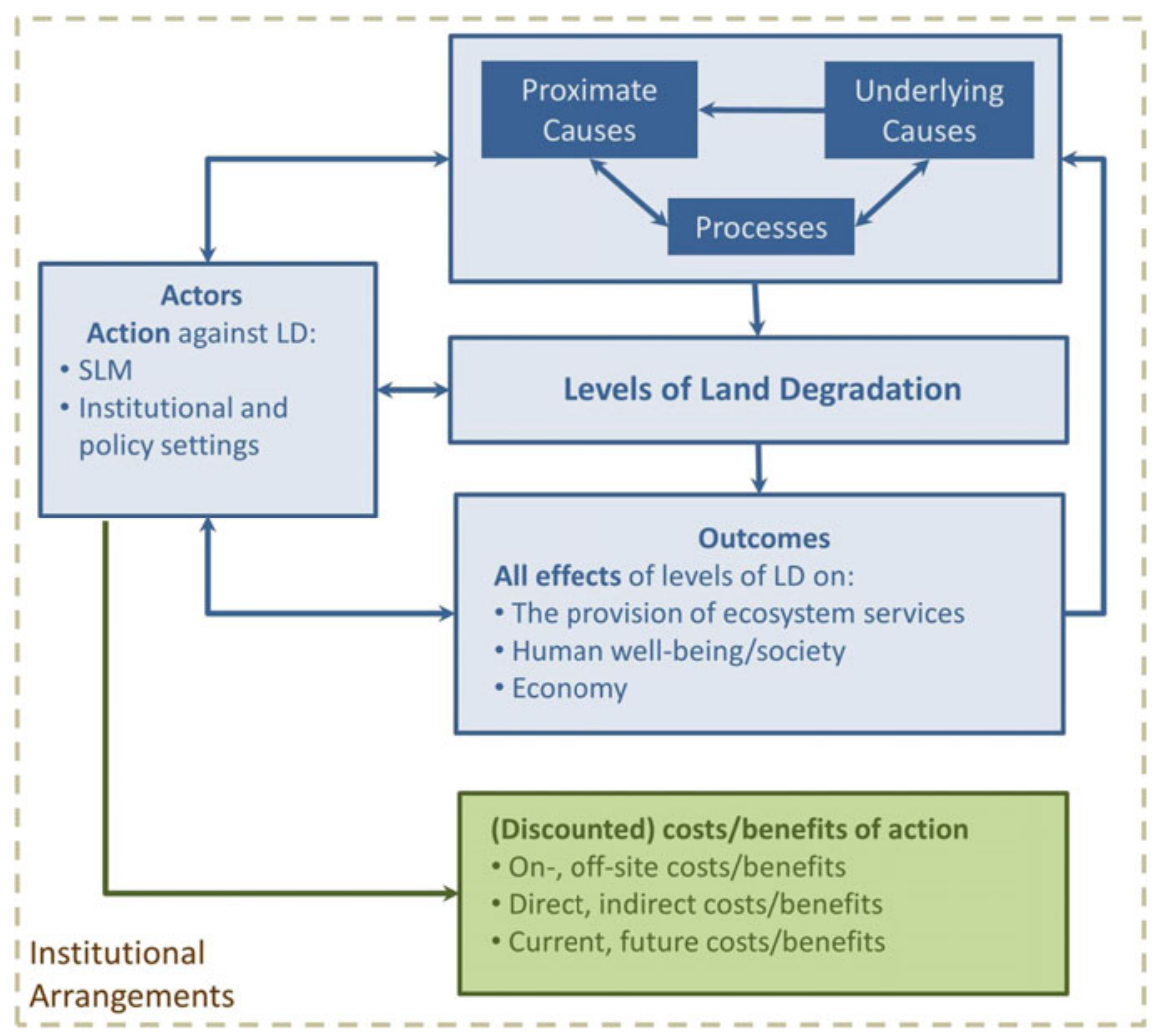

Fig. 2.1 The conceptual framework (Source Adapted from Nkonya et al. (2011))

degradation (Way 2006; Cleaver and Schreiber 1994; Scherr 2000). Understanding of the causes of land degradation and of their interactions is essential for identifying relevant actions for addressing land degradation. Therefore, as we will see further, the first step in the empirical ELD research involves the analysis of both proximate and underlying causes of land degradation.

Inaction against land degradation would lead to continuation, even acceleration, of land degradation and of its associated costs. However, besides its benefits, action against land degradation also involves costs - the costs of specific measures and economy-wide indirect effects-that is, opportunity costs, involving resources devoted for these actions which cannot be used elsewhere. The ultimate goal of the present conceptual framework is to compare the costs and benefits of action against land degradation versus the costs of inaction.

The level of land degradation determines its outcomes or effects - whether on-site or offsite - on the provision of ecosystem services and the benefits humans derive from those services. Other methods are also used to measure the on-site and off-site flow and stock of ecosystems services. Of particular importance is the life cycle analysis (LCA), which assesses the environmental impacts of a product during its 
life cycle (Rebitzer et al. 2004). In what is known as the environmental impact of products from its cradle to its grave, impact categories of a product and the corresponding indicators and model(s) are identified (Reap et al. 2008). The impact results are then grouped into different categories (Ibid). Despite its popularity of LCA and codification in the International Standardization Organization, LCA has a number of weaknesses (ibid.). There is no consensus on types of stressors, impacts, the models to use and corresponding indicators under consideration (ibid). Like TEV, double counting remains a major problem of LCA (ibid). Due to these problems and given that TEV methods also trace the on-site and off-site impacts of the ecosystem services, the studies in this book will use the TEV approach.

Many of the services provided by ecosystems are not traded in markets, so the different actors do not pay for negative or positive effects on those ecosystems. The value of such externalities may not be considered in the farmer's land use decision, which leads to an undervaluation of land and its provision of ecosystem services. The ecosystem services should be considered as capital assets, or natural capital (Daily et al. 2011; Barbier 2011c). This natural capital should be properly valuated and managed as any other form of capital assets (Daily et al. 2000). The failure to capture these values for land ecosystems could lead to undervaluing the impact of higher rates of land degradation. To adequately account for ecosystem services in decision making, the economic values of those services have to be determined. There exist various methods to evaluate ecosystem services (Barbier 2010, 2011a, b; Nkonya et al. 2011). However, attributing economic values to ecosystem services is challenging, due to many unknowns and actual measurement constraints. The valuation of the natural capital, therefore, should follow three stages (Daily et al. 2000): (i) evaluation of alternative options, for example, degrading soil ecosystem services versus their sustainable management, (ii) measurement and identification of costs and benefits for each alternative, and (iii) comparison of costs and benefits of each of the alternatives including their long-term effects (ibid.). However, identifying and aggregating individual preferences and attached values to ecosystem services, including over time, for each alternative option, is not a straightforward task (ibid.) As economic values are linked to the number of (human) beneficiaries and the socioeconomic context, these services depend on local or regional conditions. This dependence contributes to the variability of the values (TEEB 2010).

The green square box in Fig. 2.1 deals with the economic analysis to be carried out, and the green arrow shows the flow of information that is necessary to perform the different elements of the global economic analysis. Ideally, all indirect and off-site effects should be accounted for in the economic analysis to ensure that the assessment is from society's point of view and includes all existing externalities, in addition to the private costs that are usually considered when individuals decide on land use. This assessment has to be conducted at the margin, which means that costs of small changes in the level of land degradation, which may accumulate over time, have to be identified. Bringing together the different cost and value types to fully assess total costs and benefits over time and their interactions can be done within the framework of cost-benefit analysis and mathematical modeling. In doing this, care should be taken in the choice of the discount rates because the size of the 
discount rate, as well as the length of the considered time horizon, can radically change the results. Discount rates relate to people's time preferences, with higher discount rates indicating a strong time preference and attaching a higher value to each unit of the natural resource that is consumed now rather than in the future.

Institutional arrangements, or the "rules of the game" that determine whether actors choose to act against land degradation and whether the level or type of action undertaken will effectively reduce or halt land degradation, are represented as dotted lines encapsulating the different elements of the conceptual framework. It is crucial to identify and understand these institutional arrangements in order to devise sustainable and efficient policies to combat land degradation. For example, if farmers over-irrigate, leading to salinization of the land, it must be understood why they do so. As an illustration, it may be that institutional arrangements, also referred to as distorting incentive structures, make it economically profitable for farmers to produce as much crops as possible. Missing or very low prices of irrigation may act as such an incentive in a misleading institutional setup (Rosegrant et al. 1995).

Finally, it is also essential for the analysis to identify all the important actors of land degradation, such as land users, landowners, governmental authorities, industries, and consumers, as well as identify how institutions and policies influence those actors. Transaction costs and collective versus market and state actions are to be considered.

\section{The Methodological Framework}

The methodological approaches applied throughout the chapters of this book consist of two mutually complementary lines of research, which tackle two different aspects of the research agenda described in the conceptual framework (Fig. 2.1). This first line of research is based on descriptive and econometric analysis of causes of land degradation. Here, we seek to identify the key underlying and proximate causes of land degradation. This analysis will help to identify strategies for taking action against land degradation. However, action or non-action against land degradation will depend on its costs and benefits of taking action. This justifies and links the first part to the second part of analysis, whereas the second line of research looks specifically into the costs of land degradation and net benefits from SLM.

\section{Analysis of Causes of Land Degradation}

The causes of land degradation are numerous, interrelated and complex. Quite often, the same causal factor could lead to diverging consequences in different contexts because of its varying interactions with other proximate and underlying causes of land degradation. The results imply that targeting one underlying factor is not, in itself, sufficient to address land degradation. Rather, a number of underlying and proximate 
factors need to be taken into account when designing policies to prevent or mitigate land degradation. For our model specification, it is essential not to look for only into individual causes of land degradation, but rather identify the effects of various combinations and interactions of underlying and proximate causes of land degradation in a robust manner, with appropriate handling of potential issues related to endogeneity, multicollinearity, omitted variable bias and other statistical challenges.

At the start of the empirical work, an exploratory analysis is conducted for better understanding the characteristics and trends in land degradation, the interaction of proximate and underlying causes of land degradation and other relevant socio-economic data. This exploratory analysis is used for refining the hypotheses about the causes of land degradation, which is later tested using the in-depth data in each case study country. The exploratory analysis is done using simple descriptive tools, while the results are illustrated using maps, figures and tables. For example, the correlation between poverty, government effectiveness, land tenure, environmental policies and other key causes of land degradation is overlaid with a change in NDVI or other relevant land degradation indicators. This forms useful and simple patterns to be used to enrich the econometric results. For example, data on land tenure is overlaid with change in NDVI to show areas where NDVI decreased (possible land degradation) or increased (possible land improvement) while such areas had secure land tenure or insecure land tenure.

Therefore, the proximate and underlying causes of land degradation are analyzed at two levels:

- Global at pixel level. Like in Nkonya et al. (2011), a pixel-level estimation of causes of land degradation is made. However, we improve on Nkonya et al. (2011) by using more recent data and controlling for more causes of land degradation (Chap. 7 of this volume). Moreover, NDVI values used by us are corrected for the effects of fertilization that has been shown dissimulate land degradation (Chap. 4 of this volume).

- Household level analysis in the case study countries with panel (or cross-sectional, if panel is not available) household data. Using land use change, or households' reporting of their plot level land quality, or factual measurements of land quality at the household plots, or very high resolution NDVI images, or lack of application of sustainable land management practices, as available, as an indicator for land degradation.

The choice of variables for model specification is based on theoretical grounds and previous research, which has been described in detail in Nkonya et al. (2011) and von Braun et al. (2013). Additionally they follow established literature on causes of land degradation (Meyfroidt et al. 2010; Lambin 2001; Lambin and Geist 2006, Chap. 7).

Following Meyfroidt et al. (2010), Lambin (2001), Lambin and Geist (2006) and Nkonya et al. (2011), the structural first difference model estimating causes of land degradation or land improvement at global, regional/district and household levels, using annualized data is: 


$$
\Delta \mathrm{NDVI}=\boldsymbol{\beta}_{0}+\boldsymbol{\beta}_{1} \Delta x_{1}+\boldsymbol{\beta}_{2} \Delta \boldsymbol{x}_{2}+\boldsymbol{\beta}_{3} \Delta x_{3}+\beta_{4} \Delta x_{4}+\beta_{5} \Delta z_{i}+\varepsilon_{i}
$$

where,

$\Delta \mathrm{NDVI}$ - change in the values of the NDVI between the baseline and endline periods;

$\mathrm{x}_{1}-\mathrm{a}$ vector of biophysical causes of land degradation (e.g. climate conditions, topography, soil constraints);

$\mathrm{x}_{2}-\mathrm{a}$ vector of policy-related, institutional, demographic and socio-economic causes of land degradation (e.g. population density and growth rate, urban growth, GDP per capita, agricultural intensification and growth, national, international policies directly affecting land management, government effectiveness, land tenure, etc.);

$\mathrm{x}_{3}-\mathrm{a}$ vector of variables representing access to rural services (e.g. links to extension services, road proximity or density, access to information, assess to rural credits);

$\mathrm{x}_{4}$ - vector of variables representing rural household level capital endowment, level of education, poverty level, physical capital, social capital;

$\mathrm{z}_{\mathrm{i}}$ - vector of fixed effect variables, including administrative divisions (region, NDVI prior to the baseline period, etc.).

Alternatively, this model could be estimated using fixed effects approach instead of the first difference approach. The choice between first difference and fixed effects estimations usually depends on the characteristics of the panel data and specifically those of the error term. We expect the error terms to follow random walk, requiring first difference estimation rather than being serially uncorrelated when fixed effects is better. However, the ultimate choice between first difference and fixed effects should be made based on the characteristics of the actual data used. Various appropriate interactions and nonlinear relationships among specific variables are also tested following theoretical expectations. The results of this model are triangulated whenever possible using alternative measures of land degradation as dependent variable (such as actual soil quality measurements, etc.).

The use of NDVI or other satellite-derived measures as proxies of land degradation may, in some cases, lead to less accurate results as NDVI or other satellite-derived indicators may not be fully collinear with land degradation processes on the ground. For example, NDVI cannot easily differentiate between composition changes in vegetation, hence can lead to misleading conclusions when secondary salinization leads to abandonment of previously agricultural areas and replacement of agricultural crops by halophytic weeds. To minimize such inaccuracies, ground-truthing of satellite-derived data is conducted. More specifically, sub-national ground-truthing studies are conducted in some case study countries to assess land degradation using local-specific data to triangulate the results with the global satellite-based analysis.

However, NDVI pixels could be too big to make any meaningful conclusions at the household level. To address this problem, the above equation, which is more 
suited to global level analyses, is modified taking alternative household-level indicators of land quality as the dependent variable, such as land use change, or households' reporting of their plot level land quality, or the lack of application of 3 practices, factual measurements of land quality at the household plots, or very high resolution NDVI data, as available. The explanatory variables are also at the household level:

$$
\Delta \mathrm{H}=\boldsymbol{\beta}_{0}+\boldsymbol{\beta}_{1} \Delta x_{1}+\boldsymbol{\beta}_{2} \Delta \boldsymbol{x}_{2}+\boldsymbol{\beta}_{3} \Delta \boldsymbol{x}_{3}+\boldsymbol{\beta}_{4} \Delta \boldsymbol{x}_{4}+\boldsymbol{\beta}_{5} \Delta z_{i}+\varepsilon_{i}
$$

where,

$\mathrm{H}=$ household land quality indicator;

$\mathrm{x}_{1}=\mathrm{a}$ vector of biophysical causes of land degradation (e.g. climate conditions, topography, soil constraints) at household plots;

$\mathrm{x}_{2}=\mathrm{a}$ vector of policy-related, institutional, demographic and socio-economic causes of land degradation (e.g. household income per capita, family labor availability, fertilizer/manure application rates, land tenure, etc.);

$\mathrm{x}_{3}=\mathrm{a}$ vector of variables representing access to rural services (e.g. links to extension services, road proximity or density, access to information, assess to rural credits);

$\mathrm{x}_{4}=$ vector of variables representing household level asset endowments, level of education, poverty level, physical capital, social capital;

$\mathrm{Z}_{\mathrm{i}}=$ vector of fixed effect variables, including administrative divisions, household fixed effects, etc.

Similarly, here as well, an alternative fixed effects model will also be considered. In case of cross-sectional data, the panel estimation approach will be replaced by methods suitable for cross-sectional data. Various appropriate interactions and nonlinear relationships among specific variables will be tested following theoretical expectations.

\section{Cost and Benefits of Action Versus Inaction Against Land Degradation}

The TEV approach is required to comprehensively capture the costs of land degradation. It consists of use and non-use values (Remoundou et al. 2009). The use value is further divided into direct and indirect use. The direct use includes marketed outputs involving priced consumption (e.g. crop production, fisheries, tourism, etc.) as well as un-priced benefits such as local culture and recreation. The indirect use value consists of un-priced ecosystem functions such as water purification, carbon sequestration, etc. Non-use value is divided into bequest, altruistic and existence values, all of which represent the un-priced benefits. In between these two major categories, there is the option value, which includes both marketable outputs and ecosystem services for future direct or indirect use. It is usually 
challenging to measure the non-use and indirect use values as mostly they are not traded in markets. An additional challenge of measuring TEV is the potential of double-counting of benefits from ecosystems services (Barbier 2010). Following Balmford et al. (2008) and others, care is taken to avoid double counting, by partitioning the broad but closely related benefits and process and traced their links such that they avoided double-counting (ibid).

Since we follow the broad definition of land degradation which captures the on-site and off-site effects of land management, we use social costs and benefits of land degradation. The social cost and benefit of action against land degradation and inaction is given by the net present value (NPV) for taking action against land degradation in year $\mathrm{t}$ for the land users planning horizon $\mathrm{T}$ :

$$
\pi_{t}^{c}=\frac{1}{\rho^{t}} \sum_{t=0}^{T}\left(P Y_{t}^{c}+I V_{t}+N U_{t}+b_{t}^{c}-l m_{t}^{c}-c_{t}^{c}-\tau_{t}^{c}\right)
$$

where, $\pi_{t}^{c}=$ net present value (NPV) for taking action against land degradation in year $\mathrm{t}$ for the land users planning horizon $\mathrm{T} ; Y_{t}^{c}=$ production of direct use provisioning services when using SLM practices; $\mathrm{P}=$ unit price of $Y_{t}^{c} ; \mathrm{IVt}=$ indirect use value; NUt $=$ on-site non-use value; $b_{t}^{c}=$ off-site positive benefit of SLM practices; $\rho t=1+\mathrm{r}, \mathrm{r}=$ land user's discount rate; $l m_{t}^{c}=$ cost of SLM practices; $c_{t}^{c}=$ direct costs of production other than land management; $\tau_{t}^{c}=$ off-site costs of SLMincluding use and non-use costs. The term $\tau_{t}^{c}$ implies that even SLM could produce negative off-site costs. For example, application of chemical fertilizer leads to greenhouse gas emission. $1 \mathrm{~kg}$ of nitrogen requires about $3 \mathrm{~kg}$ of $\mathrm{CO}_{2}$-equivalent (Vlek et al. 2004) because of the high energy requirement for the manufacture and transport of fertilizer.

If land user does not take action against land degradation, the corresponding NPV is given by

$$
\pi_{t}^{d}=\frac{1}{\rho^{t}} \sum_{t=0}^{T}\left(P Y_{t}^{d}+I V_{t}+N U_{t}+b_{t}^{d}-l m_{t}^{d}-c_{t}^{d}-\tau_{t}^{d}\right)
$$

where $\pi_{t}^{d}=\mathrm{NPV}$ when land user uses land degrading practices. All other variables are as defined in above but with superscript $d$ indicating land degrading practices.

The benefit of taking action against land degradation is given by $B A=\pi_{t}^{c}-\pi_{t}^{d}$.

The difference $\pi_{\mathrm{t}}^{\mathrm{c}}-\pi_{\mathrm{t}}^{\mathrm{d}}$ plays an important role in land users' decision making during their planning horizon T. Table 2.1 summarizes the actions of land users when returns to SLM are smaller, greater or equal to the corresponding returns to SLM. If the returns to land management for the SLM are smaller than the corresponding returns for land degrading practices, the land user is likely to use land degrading practices.

However, given that prevention of land degradation is expected to be cheaper than rehabilitation of degraded lands, it is always prudent to prevent land degradation. The 
Table 2.1 Action versus inaction decisions at different levels

\begin{tabular}{l|l}
\hline$\pi_{t}^{c}-\pi_{t}^{d}$ & Logical action/inaction \\
\hline$>0$ & Take action against LD \\
\hline$<0$ & $\begin{array}{l}\text { Don't take action. Alternatively provide incentives to take action against land } \\
\text { degradation (e.g. PES }{ }^{\mathrm{a}} \text { ) }\end{array}$ \\
\hline$=0$ & $\begin{array}{l}\text { Indifferent, hence provide incentives to take action against land degradation } \\
\text { (e.g. PES) }\end{array}$ \\
\hline
\end{tabular}

Note Taking action against land degradation include: prevention of land degradation or

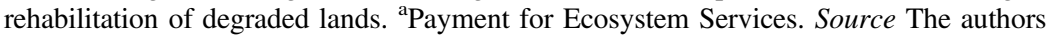

challenge is internalization of SLM benefits and enhancing adoption of SLM practices for low income farmers who may not have paid to adopt SLM. For example, payment for ecosystem services (PES) could be used when BA $\leq 0$ (see Table 2.1).

\section{Sampling Framework for Case Studies}

Proximate and underlying causes of land degradation are intricately embedded in their specific local contexts (Nkonya et al. 2011; von Braun et al. 2013), and hence, only through comprehensive analysis of these local heterogeneous interactions that meaningful insights could be derived about causes and necessary actions against land degradation. On the other hand, needless to say that these insights should not be exclusively limited only to some specific local settings, but should have a global relevance. In this regard, case study methodology is a preferred choice of method when the phenomenon being studied is indistinguishable from its context (Yin 2003) - which enables to achieve the first objective of local thoroughness. The second objective of global relevance is achieved by designing a rigorous sampling framework with theoretically sound case study selection strategy.

Extrapolation of case study findings beyond these case studies themselves is possible only when the case study design has been based on theoretical grounds: where specific research questions are asked to test the validity of rival explanations of cause-and-effect relationships in land degradation. Carefully selected multiple case studies are the means to provide a more convincing test of a theory and specify conditions under which different, perhaps even opposing, theories could be valid (De Vaus 2001). Moreover, the external validity of a case study depends on its capacity for theoretical generalization, rather than statistical generalization which is conducted through probability-based random sampling techniques. In that sense, case studies are like experiments with replications: if the theoretical insights gained from case studies conducted in multiple settings coincide, then the potential of external validity of these results is higher. To achieve such external validity, case studies are selected not statistically, but "strategically" (ibid.), which necessitates selecting those cases which will enable to rigorously test the causal relationships in different contexts (ibid.). Moreover, random probability based selection of countries 
is also practically infeasible within realistic time and budget constraints. Finally, it is essential that the core research methodologies and protocols in each of the case studies should be similar for ensuring comparability of their results.

For conducting this global economic analysis of land degradation, case study countries have been carefully selected based on purposive sampling framework and maximum variation approach, where it was sought to comprehensively capture a wide spectrum of heterogeneous contexts of land degradation in order to test rival cause-and-effect hypotheses about land degradation. Thus, the main objective in the sampling was to ensure the external validity and global relevance of the selected case study countries for a big heterogeneity of land degradation, institutional and socio-economic situations around the world.

The sampling strategy consisted of three steps:

First, earlier analyses of causes of land degradation have identified such key socio-economic and institutional underlying factors of land degradation as per capita GDP, population density, government effectiveness and agricultural intensification (Nkonya et al. 2011). Based on these characteristics, the countries of the world have been clustered using K-means clustering technique into seven clusters with more homogenous within-cluster characteristics (Table 2.2). The decision on the optimal number of clusters was guided both by the results of the formal statistical Calinski-Harabasz stopping rule (Calinski and Harabasz 1974), ${ }^{1}$ and graphical and numerical exploratory analysis of the data. Second, the selected clusters were formally validated against several key socio-economic and biophysical variables, which were not part of the initial clustering, such as long-term changes in remotely-sensed NDVI values (Tucker et al. 2004), which can be used as a potential proxy for land degradation, share of rural population in the total, share of agriculture in GDP, average cereal yields per hectare. The identified clusters showed significant differences for each of these variables, thus providing a strong evidence for the validity of the clustering approach employed (Table 2.2 and Fig. 2.2). Third, once the countries have been put through these selection filters to ensure their representativeness of global heterogeneity in terms of socio-economic, institutional and land degradation characteristics, countries were selected from each cluster for in-depth case studies, based on such additional criteria as i) regional representativeness, ii) the selected countries have collected or are collecting the data required for the assessment.

This selection of countries is highly and sufficiently heterogeneous in terms of both biophysical, socio-economic and institutional characteristics to enable rigorous ground-level testing of various causal hypotheses about land degradation, and for specifying which causal relationships could be prevailing under each of these different interactions of factors. The representativeness of the case study countries is also demonstrated by their good coverage of the world biomes (Fig. 2.2). Moreover, these globally representative case studies also allow for achieving the objective of

\footnotetext{
${ }^{1}$ Milligan and Cooper (1985) conclude, using a Monte Carlo simulation, that Calinsky-Harabasz stopping rule provides the best results among the 30 stopping rules they have compared.
} 


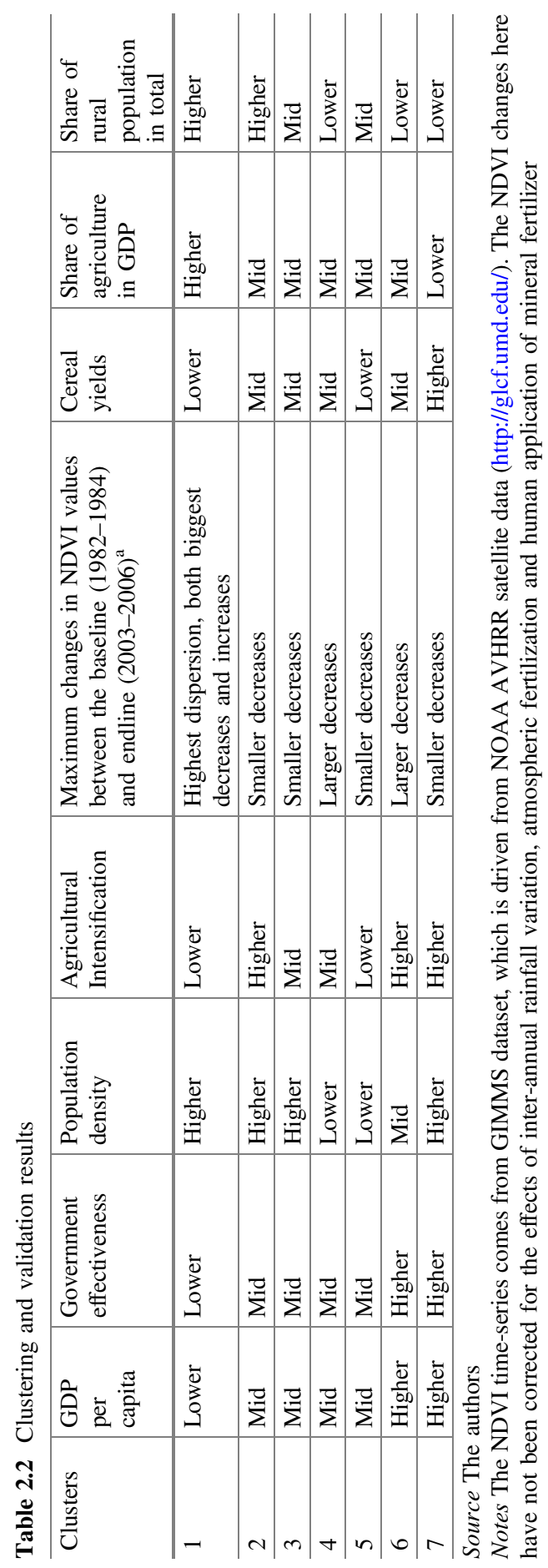




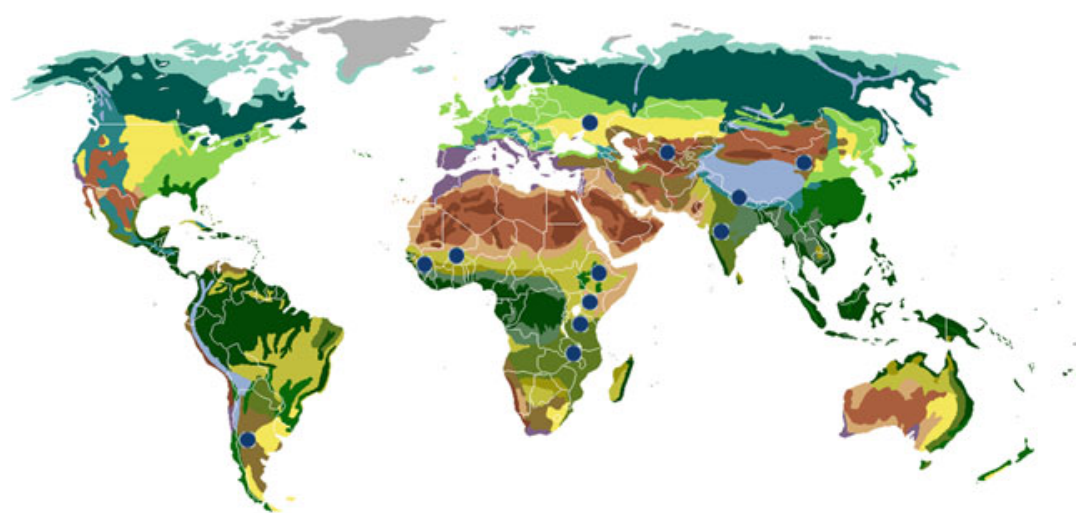

Fig. 2.2 Global Map showing the correspondence of case study countries to major global biomes (Source Modified from Wikipedia Commons, from http://commons.wikimedia.org/wiki/File: Vegetation-no-legend.PNG, accessed on 08 October 2013. Selected case study countries are identified by blue circles, and include: Argentina, Bhutan, China, Ethiopia, India, Kenya, Malawi, Niger, Tanzania, Russia, Senegal and Uzbekistan.)

providing national and global-level estimates of costs of land degradation and net benefits of taking action against it through SLM investments and policies. The 12 selected case study countries account for $43 \%$ of the global population and $28 \%$ of the land area.

Given higher levels of development challenges and opportunities posed by land degradation impacts, Cluster 1 countries, mostly from sub-Saharan Africa, are given higher weight in this particular selection. Naturally, the more is the number of case study countries, the higher is the accuracy of generalizations.

Following this sampling framework, and using the European Joint Research Center (JRC) guidelines (Toth et al. 2012), the data collected from the case study countries will be interpolated across the corresponding farming systems within the same cluster or the same region. No interpolation will be made across regions. For example, no data from sub-Saharan Africa will be interpolated to Latin America or Asia. This is because the interpolation within a region increases the accuracy of results as there are unobservable characteristics that could play an important role in causing land degradation. Interpolating within a region minimizes such omitted variable effects.

\section{Conclusions and Reflections}

There have been numerous but isolated attempts in the past to assess the causes and consequences of land degradation. However, the differences in concepts and methodologies did not allow for their meaningful comparison, and quite often have led to contradicting policy conclusions. Only if some basic standards are identified 
and adhered to, comparative assessments can be conducted between countries and useful aggregation of findings, based on these case studies, can be achieved. This is quite important for making impact on policy for investment and land use, and for getting land degradation problems out of their current obscurity. The proposed framework can provide a consistent conceptual basis for other ongoing or future similar research activities on economics of land degradation and improvement.

Certainly, causes, consequences and solutions for land degradation problems are not limited to agriculture alone. Reducing poverty, enhancing food security, promoting rural development through addressing land degradation, require that the applied methodologies need to involve all the relevant sectors, institutions, and policies. It is also true that one needs to start somewhere-without any doubt, agriculture is at the heart of land degradation problems, and while the other sectors need to be included too. It is also crucial to incorporate ecosystem values in assessing the costs of land degradation, in addition to direct costs. Many of the services provided by ecosystems are not traded in markets, so the different actors do not pay for negative or positive effects on those ecosystems. The value of such externalities may not be considered in the farmer's land use decision, which leads to an undervaluation of land and its provision of ecosystem services.

What is proposed here is a comprehensive conceptual framework for conducting the ELD assessment, concentrating on two core analytical methods demonstrating the use of methodological standards to guide other ELD case studies: (1) identification of causes of land degradation, (2) economic modeling of action versus inaction against land degradation. However, the conceptual framework represents a forward-looking agenda which can guide future research to fill the other elements of this comprehensive framework. Therefore, building national and international capacities, mobilizing bottom-up national research and action against land degradation is one of the key expectations from this research work.

Open Access This chapter is distributed under the terms of the Creative Commons Attribution Noncommercial License, which permits any noncommercial use, distribution, and reproduction in any medium, provided the original author(s) and source are credited.

\section{References}

Balmford, A., Rodrigues, A., Walpole, M., Ten Brink, P., Kettunen, M., Braat, L., \& De Groot, R. (2008). Review on the economics of biodiversity loss: scoping the science. Cambridge, UK: European Commission.

Barbier, E. B. (2011a). Capitalizing on nature: Ecosystems as natural assets. Cambridge and New York: Cambridge University Press. 321 pp.

Barbier, E. B. (2011b). Pricing nature. Annual Review of Resource Economics, 3, 337-353.

Barbier, E. (2011c). Capitalizing on nature: Ecosystems as natural assets. Cambridge, UK; New York: Cambridge University Press.

Barbier, E. B., Hacker, S. D., Kennedy, C., Koch, E. W., Stier, A. C., \& Silliman, B. R. (2010). The value of estuarine and coastal ecosystem services. Ecological Monographs, 81(2), 169193. doi:10.1890/10-1510.1. 
Caliński, T., \& Harabasz, J. (1974). A dendrite method for cluster analysis. Communications in Statistics-theory and Methods, 3(1), 1-27.

Chapin, F. S. I., Zavaleta, E. S., Eviner, V. T., Naylor, R. L., Vitousek, P. M., Reynolds, H. L., et al. (2000). Consequences of changing biodiversity. Nature, 405, 234-242.

Cleaver, K. M., \& Schreiber, G. A. (1994). Reversing the Spiral: The Population, Agriculture, and Environment Nexus in Sub-Saharan Africa. Washington, DC: The World Bank.

Daily, G. C., Kareiva, P. M., Polasky, S., Ricketts, T. H., \& Tallis, H. (2011). Mainstreaming natural capital into decisions. Natural Capital: Theory and Practice of Mapping Ecosystem Services, 3-14.

Daily, G. C., Söderqvist, T., Aniyar, S., Arrow, K., Dasgupta, P., Ehrlich, P. R., et al. (2000). The value of nature and the nature of value. Science, 289(5478), 395-396. doi:10.1126/science.289. 5478.395.

De Vaus, D. A. (2001). Research design in social research. London: SAGE.

Foley, J. A., DeFries, R., Asner, G. P., Barford, C., Bonan, G., Carpenter, S. R., et al. (2005). Global consequences of land use. Science, 309, 570-574.

Lal, R., Safriel, U., \& Boer, B. (2012). Zero net land degradation: A new sustainable development goal for Rio +20 . A report prepared for the Secretariat of the United Nations Convention to Combat Desertification.

Lambin, E. (2001). Predicting land-use change. Agriculture, Ecosystems \& Environment, 85(1-3), $1-6$.

Lambin, E. F., \& Geist, H. (Eds). (2006). Land-use and land-cover change local processes and global impacts. Berlin: Springer.

Le, Q. B. (2012) Indicators of global soils and land degradation. Slides of oral presentation at the first global soil week, 18-22 Nov 2012, Berlin, Germany. The First Global Soil Week, Berlin.

Le, Q. B., Tamene, L., \& Vlek, P. L. G. (2012). Multi-pronged assessment of land degradation in West Africa to assess the importance of atmospheric fertilization in masking the processes involved. Global and Planetary Change, 92-93, 71-81.

MEA (Millenium Ecosystem Assessment). (2005). Dryland Systems. In R. Hassan, R. Scholes, \& N. Ash (Eds.), Ecosystem and well-being: Current state and trends (pp. 623-662). Washington, DC: Island Press.

Meyfroidt, P., Rudel, T. K., Lambin, E. (2010). Forest transitions, trade, and the global displacement of land use. Proceedings of the National Academy of Sciences, 107(49), 20917 20922, www.pnas.org/cgi/doi/10.1073/pnas.1014773107

Milligan, G., \& Cooper, M. (1985). An examination of procedures for determining the number of clusters in a data set. Psychometrika, 50(2), 159-179. doi:10.1007/bf02294245.

Nachtergaele, F., Petri, M., Biancalani, R., Van Lynden, G., \& Van Velthuizen, H. (2010). Global land degradation information system (GLADIS). Beta version. An information database for land degradation assessment at global level. Land degradation assessment in drylands technical report, no. 17. FAO, Rome, Italy.

Nkonya, E., Gerber, N., Baumgartner, P., von Braun, J., De Pinto, A., Graw, V., et al. (2011). The economics of desertification, land degradation, and drought-toward an integrated global assessment. ZEF-Discussion Papers on Development Policy No. 150, Center for Development Research (ZEF), Bonn, Germany.

Reap, R., Roman, F., Duncan, S., \& Bras, B. (2008). A survey of unresolved problems in life cycle assessment. The International Journal of Life Cycle Assessment., 3(5), 374-388.

Reay, D. S., Dentener, F., Smith, P., Grace, J., \& Feely, R. (2008). Global nitrogen deposition and carbon sinks. Nature Geoscience, 1, 430-437.

Rebitzer, G., Ekvall, T., Frischknecht, R., Hunkeler, D., Norris, G., Rydberg, T., et al. (2004). Life cycle assessment part 1: Framework, goal and scope definition, inventory analysis, and applications. Environment International, 30, 701-720.

Remoundou, K., Koundouri, P., Kontogianni, A., Nunes, P. A. L. D., \& Skourtos, M. (2009). Valuation of natural marine ecosystems: an economic perspective. Environmental Science \& Policy, 12(7), 1040-1051. doi:10.1016/j.envsci.2009.06.006. 
Rosegrant, M. W., Schleyer, R. G., \& Yadav, S. N. (1995). Water policy for efficient agricultural diversification: market-based approaches. Food Policy, 20(3), 203-223. doi:10.1016/03069192(95)00014-6.

Safriel, U. N. (2007). The assessment of global trends in land degradation. In: M. V. K. Sivakumar $\&$ N. Ndiang'ui. (Eds.), Climate and land degradation (pp. 1-38). Berlin: Springer.

Sala, O. E., Chapin, F. S. I., Armesto, J. J., Berlow, E., Bloomfield, J., Dirzo, R., et al. (2000). Global biodiversity scenarios for the year 2100. Science, 287, 1770-1774.

Scherr, S. (2000). Downward spiral? Research evidence on the relationship between poverty and natural resource degradation. Food Policy, 25(4), 479-498.

TEEB (The Economics of Ecosystems and Biodiversity). (2010). Mainstreaming the economics of nature: A synthesis of the approach, conclusions and recommendations of TEEB. Malta.

TerrAfrica. (2006). Assessment of the nature and extent of barriers and bottlenecks to scaling sustainable land management investments throughout sub-Saharan Africa. Unpublished TerrAfrica report.

Toth, K., Portele, C., Illert, A., Lutz, M., \& Nunes de Lima, V. (2012). A conceptual model for developing interoperability specifications in spatial data infrastructures. JRC Reference Reports. Online at http://ec.europa.eu/dgs/jrc/index.cfm?id=2540

Tucker, C. J., Pinzon, J. E., \& Brown, M. E. (2004) Global inventory modeling and mapping studies. NA94apr15b.n11-VIg, 2.0, Global Land Cover Facility, University of Maryland, College Park, Maryland, USA.

UNCCD (United Nations Convention to Combat Desertification). (1996). United Nations convention to combat desertification in countries experiencing serious drought and/or desertification. Germany: Bonn.

Vlek, P., Le, Q. B., \& Tamene, L. (2010). Assessment of land degradation, its possible causes and threat to food security in Sub-Saharan Africa. In R. Lal \& B. A. Stewart (Eds.), Food security and soil quality (pp. 57-86). Boca Raton, Florida: CRC Press.

Vlek, P., Rodriguez-Kuhl, G., \& Sommer, R. (2004). Energy use and $\mathrm{CO}_{2}$ production in tropical agriculture and means and strategies for Reduction or mitigation Environment. Development and Sustainability, 6, 213-233.

Vogt, J. V., Safriel, U. N., Von Maltitz, G., Sokona, Y., Zougmore, R., Bastin, G., \& Hill, J. (2011). Monitoring and assessment of land degradation and desertification: Towards new conceptual and integrated approaches. Land Degradation \& Development, 22, 150-165.

von Braun, J., Gerber, N., Mirzabaev, A., \& Nkonya, E. (2013). The economics of land degradation. (ZEF Working Papers 109). Bonn, Germany.

Wassen, M. J., Olde Venterink, H., Lapshina, E. D., \& Tanneberger, F. (2005). Endangered plants persist under phosphorus limitation. Nature, 437, 547-550.

Way, S. A. (2006). Examining the Links between poverty and land degradation: From blaming the poor toward recognizing the rights of the poor. In P. Johnson, K. Mayrand, \& M. Paquin (Eds.), Governing Global Desertification: Linking Environmental Degradation, Poverty, and Participation (pp. 27-41). VT: Ashgate, Burlington.

World Meteorological Organization. (2012). WMO greenhouse gases bulletin: the state of greenhouse gases in the atmosphere using global observations through 2011. Switzerland: WMO Greenhouse Gas Bulletin.

Yin, R. K. (2003). Applications of case study research. Thousand Oaks, California: Sage Publications. 